\title{
Chapter 72 \\ Thermal Performance of Fly Ash \\ Geopolymeric Mortars Containing Phase Change Materials
}

This paper reports experimental results on the thermal performance of fly ash-based 6 geopolymeric mortars containing different percentages of phase change materials 7 (PCMs). These materials have a twofold eco-efficient positive impact. On one hand, 8 the geopolymeric mortar is based on industrial waste material. And on the other 9 hand, the mortars with PCM have the capacity to enhance the thermal performance 10 of the buildings. Several geopolymeric mortars with different PCM percentages 11 $(10 \%, 20 \%, 30 \%)$ were studied for thermal conductivity and thermal energy storage. 12

\section{Introduction}

Climate change-related effects are associated mainly to the emissions of energy 14 sector [1]. This in turn is dependent on the population rise that will be responsible for 15 a very high increase of electricity demand [2]. The energy needs of the building 16 sector are expected to grow more than 70\% [3]. The European Union adopted very 17 ambitious plans in order to tackle this paramount problem. The European Energy 18 Performance of Buildings Directive (EPBD) 2002/91/EC has [4] required that by the 19 end of 2018, all new buildings must have a nearly zero-energy consumption. The use 20 of innovative materials like PCMs will make it easier for this target to be met 21 [5]. These materials use chemical bonds to store or release heat thus allowing for a 22 reduction on the energy consumption. The capability to store or release thermal 23

M. Kheradmand · M. Azenha

University of Minho, Guimarães, Portugal

F. Pacheco Torgal $(\bowtie)$

University of Minho, Guimarães, Portugal

University of Sungkyunkwan, Suwon, Republic of Korea

e-mail: torgal@civil.uminho.pt 
t1.1 Table 72.1 Major oxides in fly ash (\%)

60.8

$\mathrm{Al}_{2} \mathrm{O}_{3}$

Table 72.2 Properties of PCMs

\begin{tabular}{ll|l|l|l|l}
\hline t2.2 & $\begin{array}{l}\text { Operating } \\
\text { temperature range } \\
\left({ }^{\circ} \mathrm{C}\right)\end{array}$ & $\begin{array}{l}\text { Latent heat of } \\
\text { fusion }(\mathrm{J} / \mathrm{g})\end{array}$ & $\begin{array}{l}\text { Melting } \\
\text { point }\left({ }^{\circ} \mathrm{C}\right)\end{array}$ & $\begin{array}{l}\text { Apparent density at } \\
\text { solid state }(\mathrm{kg} / \mathrm{m} 3)\end{array}$ & $\begin{array}{l}\text { Particle size } \\
\text { distribution range } \\
(\boldsymbol{\mu} \mathrm{m})\end{array}$ \\
\cline { 2 - 6 } t2.3 & $10-30$ & 110 & 26 & 350 & $5-90$ \\
\hline
\end{tabular}


The specimens were cured in laboratory conditions $\left(25^{\circ} \mathrm{C}\right.$ and $65 \%$ relative 53 humidity (RH)). The thermal conductivities of the mortars were determined in four 54 representative measurements of each mortar formulation, using a steady-state heat 55 flow metre apparatus (ALAMBETA, Model Sensora), following recommendation of 56 ISO 8301:1991 [14]. Mortars were casted into cylinder moulds with diameter of 57 $10 \mathrm{~cm}$ and length of $1 \mathrm{~cm}$. Then thermal conductivity of the specimen is calculated 58 based on heat conduction heat transfer theory according to [15]. Specific enthalpies 59 of the mortars were determined using, it is relevant to submit the sample into the 60 differential scanning calorimeter-DSC testing (Model NETZSCH 200 F3 Maia) and 61 measure the corresponding heat fluxes at controlled environment. Based on this, the 62 specific heat as a function of temperature can be obtained, and the specific enthalpy 63 is determined. The DSC has an accuracy of $\pm 0.2{ }^{\circ} \mathrm{C}$ for temperature measurements. 64 All the specimens were tested within aluminium crucibles with volume of $40 \mu \mathrm{L} 65$ under nitrogen $\left(\mathrm{N}_{2}\right)$ atmosphere with a flow of $50 \mathrm{~mL} / \mathrm{min}$. The specimens were 66 weighted using analytical balance (model PerkinElmer AD-4) with accuracy of 67 $\pm 0.01 \mathrm{mg}$. Each specimen was sealed in the pan by using an encapsulating press. 68 An empty aluminium crucible was considered a reference in all measurements. A 69 heating/cooling rate of $5{ }^{\circ} \mathrm{C} / \mathrm{min}$ was considered for all experiments.

\section{Results and Discussion}

The thermal conductivity results are presented in Table 72.3. The lowest thermal 72 conductivity is noticed for the mixtures based on a sodium silicate/sodium hydroxide 73 ratio of 2.5 and an activator/binder ratio of 0.7 . For a similar activator/binder ratio, 74 the reduction of the sodium silicate/sodium hydroxide ratio to 2.0 leads to highest 75 results of thermal conductivity. Results show that the addition of PCM into the 76 different mortars results in a consistent reduction of thermal conductivities. The 77 highest reduction is noticed for the mixtures based on a sodium silicate/sodium 78 hydroxide ratio of 2.0 and an activator/binder ratio of 0.7 . The DSC curves for the 79 testing of mortars at heating/cooling rate of $5{ }^{\circ} \mathrm{C} / \mathrm{min}$ are shown in Fig. 72.1.

Table 72.3 Thermal conductivity of mortars

\begin{tabular}{l|l|l}
\hline Formulations & Group name & Thermal conductivity (W/m. K) \\
\hline 12M_2.5S/H_0.8A/B & A & 0.77 \\
\hline 10PCM_12M_2.5S/H_0.8A/B & A & 0.70 \\
\hline 20PCM_12M_2.5S/H_0.8A/B & A & 0.69 \\
\hline 30PCM_12M_2.5S/H_0.8A/B & A & 0.44 \\
\hline 12M_2.5S/H_0.7A/B_1.0SP & B & 0.52 \\
\hline 10PCM_12M_2.5S/H_0.7A/B_1.5SP & B & 0.47 \\
\hline 20PCM_12M_2.5S/H_0.7A/B_1.5SP & B & 0.44 \\
\hline 30PCM_12M_2.5S/H_0.7A/B_1.5SP & B & 0.42 \\
\hline 12M_2.0S/H_0.7A/B_1.0SP & C & 0.94 \\
\hline 10PCM_12M_2.0S/H_0.7A/B_1.5SP & C & 0.90 \\
\hline 20PCM_12M_2.0S/H_0.7A/B_1.5SP & C & 0.77 \\
\hline 30PCM_12M_2.0S/H_0.7A/B_1.5SP_3.0 W & C & 0.35
\end{tabular}



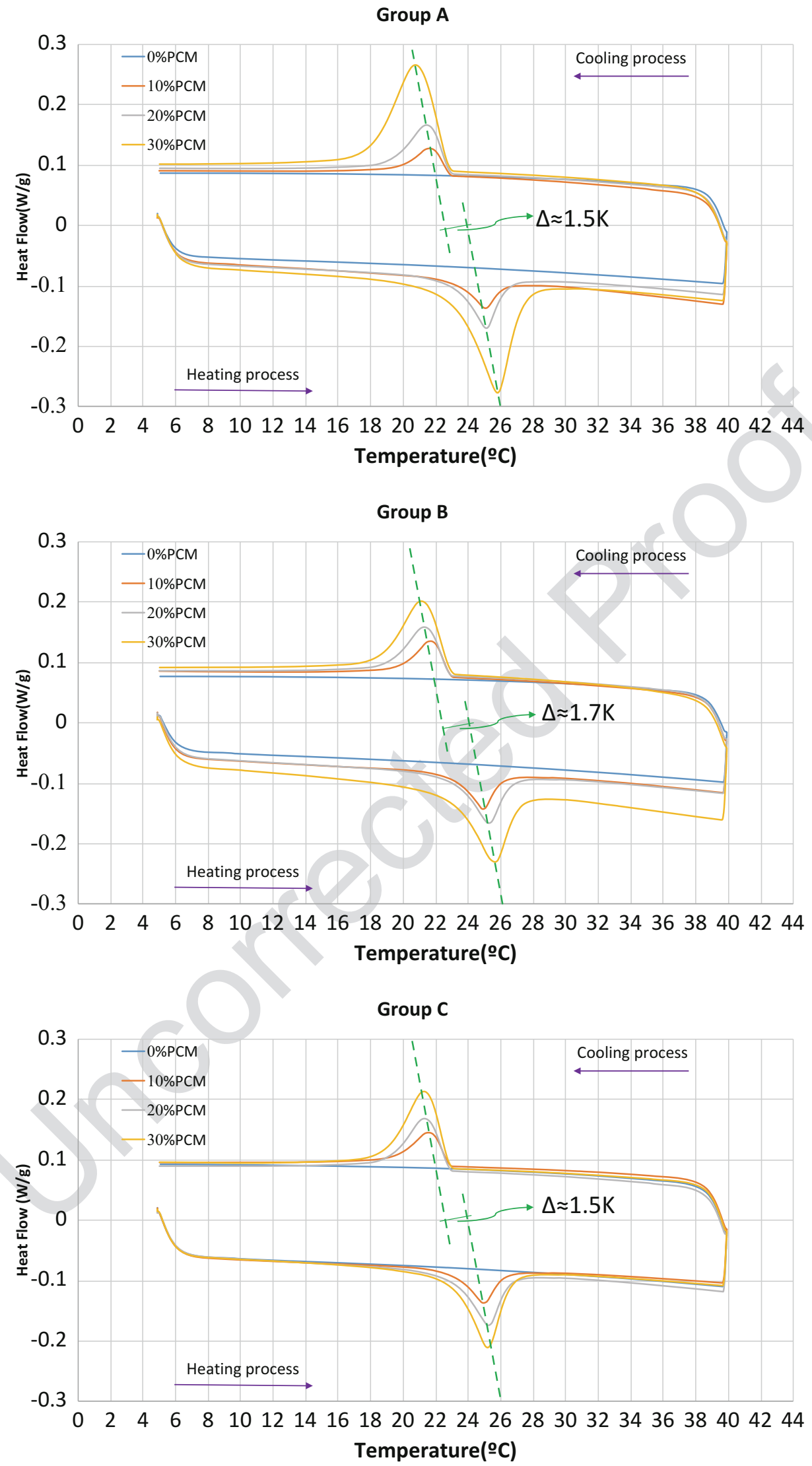

Fig. 72.1 DSC curves of the alkali-activated mortars with and without PCM upon a cooling and a heating cyclic test with a rate of $5{ }^{\circ} \mathrm{C} / \mathrm{min}$ : (a) group A based on 12M_2.5S/H_0.8A/B; (b) group B based on 12M_2.5S/H_0.7A/B_1.0SP; (c) group C based on 12M_2.0S/H_0.7A/B_1.0SP 
Overall, the results suggested that the PCM peak temperature shifts in the 81 direction of the imposed flux and further confirming higher peaks for mortars with 82 higher mass fraction of PCM into the mix. The two dashed lines per graphic have 83 been plotted by uniting the peak temperatures of all heating and all cooling thermo- 84 grams: there is a clear linear relationship between the peak temperature of the 85 thermogram and the percentage of PCM embedded. When the two dashed lines for 86 a given group are compared, it can be noticed that they are approximately parallel 87 and that the distance between them ranges from $\Delta \approx 1.5 \mathrm{~K}$ to $\Delta \approx 2.5 \mathrm{~K}$. The 88 difference observed in this hysteresis is known to depend on the internal thermal 89 gradients upon the tested sample, which tend to lag or raise heat exchange from 90 DSC. The average specific enthalpies for all the studied groups are $\approx 1.5 \mathrm{~J} / \mathrm{g}, \approx 2.5 \mathrm{~J} / 91$ $\mathrm{g}$ and $\approx 4 \mathrm{~J} / \mathrm{g}$ for the mortar with 10\%PCM, 20\%PCM and 30\%PCM, respectively. 92

\section{Conclusions}

The lowest thermal conductivity is noticed for the mixtures based on a sodium 94 silicate/sodium hydroxide ratio of 2.5 and an activator/binder ratio of 0.7 . For a 95 similar activator/binder ratio, the reduction of the sodium silicate/sodium hydroxide 96 ratio to 2.0 leads to highest results of thermal conductivity. Results show that the 97 addition of PCMs results in a consistent reduction of thermal conductivities. The 98 average specific enthalpies for all the studied groups are $\approx 1.5 \mathrm{~J} / \mathrm{g}, \approx 2.5 \mathrm{~J} / \mathrm{g}$ and $\approx 4 \mathrm{~J} / 99$ $\mathrm{g}$ for the mortar with 10\%PCM, 20\%PCM and 30\%PCM, respectively.

\section{References}

1. King, D., Browne, J., Layard, R., O’Donnell, G., Rees, M., Stern, N., \& Turner, A. (2015). A 102 global Apollo programme to combat climate change. Centre for Economic Performance, 103 London School of Economics and Political Science. http://cep.lse.ac.uk/pubs/download/spe 104 cial/Global_Apollo_Programme_Report.pdf. [Accessed 9 October 2015]. 105

2. World Bank. (2014). World development indicators: Electric power consumption per capita in 106 2011. http://wdi.worldbank.org/table/5.11

3. Ürge-Vorsatz, D., Cabeza, L., Serrano, S., Barreneche, C., \& Petrichenko, K. (2015). Heating 108 and cooling energy trends and drivers in buildings. Renewable and Sustainable Energy 109 Reviews, 41, 85-98.

4. European Union. (2010, June). Directive 2010/31/EU of the European Parliament and of the 111 Council of May 19th, 2010 on the energy performance of buildings (recast). Official Journal of 112 the European Union.

5. Pacheco-Torgal, F. (2014). Eco-efficient construction and building materials research under the 114 EU Framework Programme Horizon 2020. Construction and Building Materials, 51, 151-162. 115

6. Jelle, B., \& Kalnæs, S. (2017). Phase change materials for application in energy efficient 116 buildings. In F. Pacheco-Torgal, C. G. Granqvist, B. P. Jelle, G. P. Vanoli, N. Bianco, \& 117 J. Kurnitski (Eds.), Cost-effective energy efficient building retrofitting: Materials, technologies, 118 optimization and case studies (pp. 57-118). Cambridge: Woodhead Publishing. 
7. Cunha, S., Aguiar, J., \& Tadeu, A. (2016). Thermal performance and cost analysis of mortars made with PCM and different binders. Construction and Building Materials, 122, 637-648.

8. Cunha, S., Aguiar, J., \& Pacheco-Torgal, F. (2015). Effect of temperature on mortars with incorporation of phase change materials. Construction and Building Materials, 98, 89-101.

9. European Commission. (2011). Roadmap to a resource efficient Europe. COM(2011) 571. EC, Brussels.

10. COM. (2014, July 2). 398 final. Towards a circular economy: A zero waste programme for Europe. Communication from the Commission to the European Parliament, the Council. The European Economic and Social Committee and the Committee of the Regions. Brussels.

11. Payá, J., Monzó, J., Borrachero, M., \& Tashima, M. (2014). Reuse of aluminosilicate industrial waste materials in the production of alkali-activated concrete binders. In F. Pacheco-Torgal, J. Labrincha, A. Palomo, C. Leonelli, \& P. Chindaprasirt (Eds.), Handbook of alkali-activated cements, mortars and concretes (pp. 487-518). Cambridge, UK: WoddHead Publishing.

12. American Coal Ash Association. (2016). https://www.acaa-usa.org/Publications/ ProductionUse-Reports

13. ASTM C618 - 15. Standard specification for coal fly ash and raw or calcined natural pozzolan for use in concrete, ASTM International, West Conshohocken.

14. ISO:8301. (1991). Thermal insulation: determination of steady state thermal resistance and related properties, heat flow meter apparatus.

15. Lecompte, T., Le Bideau, P., Glouannec, P., Nortershauser, D., \& Le Masson, S. (2015). Mechanical and thermo-physical behaviour of concretes and mortars containing phase change material. Energy and Buildings, 94, 52-60. 